\title{
Determination of Five (5) Possible Contaminants in Recycled Cardboard Packages and Food Simulants Using Ultrasound Assisted Extraction Coupled to GC-MS
}

\author{
Ioanna-Efpraxia Parigoridi, Konstantoula Akrida-Demertzi, Panagiotis G. Demertzis* \\ Laboratory of Food Chemistry, Department of Chemistry, University of Ioannina, loannina, Greece \\ Email: pdemertz@uoi.gr
}

Received 7 May 2014; revised 24 June 2014; accepted 6 July 2014

Copyright $(2014$ by authors and Scientific Research Publishing Inc.

This work is licensed under the Creative Commons Attribution International License (CC BY).

http://creativecommons.org/licenses/by/4.0/

cc) (i)

\begin{abstract}
A modified analytical procedure has been developed to test for 5 organic pollutants [benzophenone, 2 diisopropylnaphthalenes (DIPNs) \{2,6- and 2,7-diisopropylnapthalene $\}$ and 2 hydrogenated terphenyls (HTPs) \{m-terphenyl and o-terphenyl\}] that can be found as residues in recycled cardboards intended for use as food packaging materials and to test for migration levels of these compounds in a food simulant (Tenax). A main objective was to develop a modified rapid and reliable method for the identification and quantification of these compounds at low concentrations. The method was based on ultrasound-assisted solvent extraction (UAE) followed by gas chromatography-mass spectrometry (GC-MS) analysis. The developed method was applied to analyze 3 commercially available recycled carton board food-packaging materials and also to study the potential migration of the 5 organic pollutants from these materials into Tenax to check if these recycled cardboards can be considered as suitable for use in direct contact with foodstuffs. The limits of detection (LODs) of standard solutions of the 5 compounds were determined at a signal-tonoise ratio of 3. The LODs and the limits of quantification (LOQs) of examined pollutants ranged between 0.005 to $0.5 \mathrm{mg} / \mathrm{kg}$, and 0.1 to $1 \mathrm{mg} / \mathrm{kg}$, respectively. The extremely low amounts of most contaminants that migrate from packaging materials to Tenax indicate that the recycled cardboards tested can be safely used for direct food contact applications.
\end{abstract}

\section{Keywords}

Gas Chromatography-Mass Spectrometry, Ultrasound-Assisted Solvent Extraction,

*Corresponding author. 


\section{Introduction}

The demand to preserve earth's natural sources and limit the wastes and the environmental pollution boosted the interest on recycling. Additionally, recycling, when used on a financial system basis, can be one important contribution to attaining a more sustainable economy. Recycling activates in a lot of areas (plastic, metal etc.) with an expanse on the use of paper and board as raw materials. The mass of paper and board used in packaging is approximately equal to the mass of all other packaging materials combined [1].

The production process of the paper as well as its uses prior to collection for recycling, may contaminate it with substances harmful to human health. A number of them can possibly be found in paper and paperboard after recycling process [2]. In a previously conducted research in our laboratory 21 harmful organic pollutants were indentified in commercially available recycled cardboards used for food packaging applications (Benzophenone, Naphtalene, Acenapthylene, Acenaphtene, Fluorene, Phenarene, Anthracene, Fluoranthene, Pyrene, Benzo[b]fluoranthene, Benzo[a]pyrene, 2,6- and 2,7-diisopropylnapthalene, m-Terphenyl, Dioctylphthalate, Di-N-butyl phthalate, Dimethyl phthalate, Diethyl phthalate, Bis(2-ethylhexyl) adipate, Bis(2-ethylhexyl) phthalate and Benzyl butyl phthalate) [3]. Among these compounds 5 of them were detected in higher concentrations and had been the subjects of the present study: 1) Benzophenone, (residue from UV-cured inks and lacquers used to print on the packaging and if cardboard was made from recycled fibers recovered from printed materials) which could readily migrate to foods packaged in cardboard even during frozen storage [4], 2) 2,6and 2,7-di-isopropyl-naphthanes (DIPNs) (a substitute for the toxicologically harmful polychlorinated benzenes in carbonless copy paper (CLCP)), which were detected in many samples of board prepared from recycled fibers, they were also identified as food contaminants and their source attributed to paper and board packages [5]-[7], 3) 2 hydrogenated terphenyls (HTPs) (m- and o-terphenyl), (residues in cardboard packages made from recycled material containing CLCP) [8].

EU has adopted a new Waste Directive (Directive 2008/98/EC), which makes provisions for collecting paper in a segregated stream and for prioritizing recycling over incineration. Almost half of the recycled paper is used as packaging material for food-packaging applications [1] [9].

The main objective of this study was to optimize a method for the identification and quantification of the above mentioned compounds at low concentrations. The method was based on ultrasound-assisted solvent extraction (UAE) followed by gas chromatography-mass spectrometry (GC-MS) analysis.

\section{Materials and Methods}

\subsection{Chemicals}

All chemicals (solvents and organic pollutants) were of analytical grade and purchased from Sigma (Taufkirchen, Germany) and Fluka (Buchs, Switzerland).

\subsection{Materials}

Three different type of recycled carton board samples (BR, R and R KRAFT) commercially used as food packaging materials, supplied by a producer company located in Greece, were used for analysis.

\subsection{Sample Preparation (Ultrasound-Assisted Solvent Extraction)}

Liquid-phase extraction of cardboard samples was performed using an ultrasonic bath (Elmasonic S10 H, Elma $\mathrm{GmbH}$, Singen, Germany). Three pieces of commercially available recycled cardboards, approximately $175 \mathrm{mg}$ each, were cut in small pieces $(5 \times 5 \mathrm{~mm})$ and extracted with $10 \mathrm{ml}$ dichloromethane in the ultrasonic bath for $25 \mathrm{~min}$ at $20^{\circ} \mathrm{C}$. The mixture was then filtered and washed with $1 \mathrm{ml}$ dichloromethane twice. The organic phase was evaporated under nitrogen till dryness, re-dissolved in $0.175 \mathrm{ml}$ dichloromethane and stored in screw cap vials for further analysis. Triplicate determinations were carried out. 


\subsection{Quantification of Surrogates-Recovery Tests}

The quantitative determination of surrogates was made by injecting the appropriate amounts of dichloromethane extracts into a GC/MS apparatus, using the external standard method. External standards of each of the organic pollutants were prepared in appropriate concentrations ranging between 0.01 and $0.5 \mu \mathrm{g} / \mathrm{ml}$ and the respective calibration curves were constructed.

Recovery experiments were carried out using virgin paperboard materials fortified by pipetting 0.05 , 0.25 , 0.50 and $1.00 \mathrm{ml}$ of the $1 \mu \mathrm{g} / \mathrm{ml}$ fortification solution to paper samples. Extraction was performed by ultrasonication, as described previously.

\subsection{Instrumentation and GC-MS Parameters}

A Hewlett-Packard 6890 series gas chromatograph equipped with a Hewlett-Packard 5973 mass selective detector was used for all analyses. Samples were separated on a $60 \mathrm{~m} \times 0.25 \mathrm{~mm}$ internal diameter HP-5 fused-silica capillary column with a film thickness of $1 \mu \mathrm{m}$ (J\&W Scientific, Folsom, USA). The column temperature was programmed as follows: the initial column temperature was $70^{\circ} \mathrm{C}$ for $3 \mathrm{~min}$, increased to $240^{\circ} \mathrm{C}$ at a rate of $30^{\circ} \mathrm{C} / \mathrm{min}$, then increased to $270^{\circ} \mathrm{C}$ at a rate of $15^{\circ} \mathrm{C} / \mathrm{min}$. Ultra high purity helium was used as the carrier gas. Its flow rate was $0.8 \mathrm{ml} / \mathrm{min}$. Injector temperature was maintained at $290^{\circ} \mathrm{C}$, and the injection volume was $1.0 \mu \mathrm{l}$ in the splitless mode. MS conditions were as follows: acquisition was performed in electron impact (EI) mode (200 $\mathrm{eV})$ by $2.92 \mathrm{scans} / \mathrm{s}$ and the mass range used was mass/charge $(\mathrm{m} / \mathrm{z}): 29$ - 550. The temperature of the transfer line was held constant at $220^{\circ} \mathrm{C}$.

Compounds were preliminary identified by the use of Wiley and NIST libraries and the identification of them was further confirmed by comparison of their linear retention indices (Kovats indices) with those of reference standards or with published data [10]-[13].

\subsection{Migration Studies into Tenax}

Approximately $0.0625 \mathrm{dm}^{2}$ (175 mg) of each of the three cardboard samples were placed on the bottom of glass vials and were evenly coated with $0.25 \mathrm{~g}$ of Tenax. The vials were sealed and placed in an oven for 2 hours at $70^{\circ} \mathrm{C}$ [14]. Triplicate determinations were carried out. After removal of the respective paper samples the migrated surrogates were extracted from Tenax, under gentle agitation for 5 min at room temperature, using $5 \mathrm{ml}$ methanol. The extraction was repeated twice. The combined extracts were concentrated under nitrogen stream and were analyzed by injecting $1 \mu \mathrm{l}$ of the methanol extracts into the GC/MS apparatus. Triplicate determinations were performed. A simulant blank (extraction of Tenax without the migration step) was tested occasionally. Samples were exposed to the simulant using single-side contact.

\section{Results and Discussion}

The investigated organic pollutants, which are usually present in recycled fiber material, are all low molecular weight, relatively non-polar, aromatic substances. These chemicals can be detected and quantified using gas chromatography coupled with mass spectrometry. They have similar chemical behavior when fibers are treated in the recycle process (poorly water-soluble, fiber-retentive, sufficiently small and mobile molecules). That makes them to resist washing during the cleaning of the pulp in the recycling process, which increases the possibility to migrate into dry (fatty) foods.

In order to identify and quantify all 5 substances in one single trial run, a modified analytical method was developed and optimized based on pre-treatment of the samples with ultrasound-assisted solvent extraction followed by GC-MS analysis. Experiments on the extraction behavior of ethanol, hexane and dichloromethane were carried out. It was found that dichloromethane showed the best extraction ability. This finding is in agreement with that of other researchers [15] [16]. During the extraction process, ice added constantly in the ultrasonic bath, to avoid the evaporation of the volatile and semi-volatile solvents and compounds, respectively.

Virgin carton board samples fortified with the appropriate amounts of pollutants and were used for method optimization.

In Figure 1, a chromatogram of a spiked virgin carton board sample with the 5 organic pollutants is presented. A main objective of this study was to develop a quick, simple and reliable GC/MS method for the determination of the selected contaminants in recycled paperboard packaging materials. It can be seen that peak resolution is 
very satisfactory for all surrogates. Moreover, the proposed GC/MS methodology allowed complete separation of all 5 contaminants within a very short time $(10.5 \mathrm{~min})$ and can be applied, eventually with appropriate modifications, for the detection of other classes of organic pollutants.

The \% recoveries of the investigated compounds are given in Table 1.

The results on Table 1 indicate that very satisfactory recoveries for all five organic pollutants were obtained.

The limits of detection (LODs) of standard solutions of the 5 surrogates were determined at a signal-to-noise ratio of 3. The LODs and the limits of quantification (LOQs) of examined pollutants ranged between 0.005 and $0.5 \mathrm{mg} / \mathrm{kg}$, and between 0.1 and $1 \mathrm{mg} / \mathrm{kg}$ respectively.

The developed methodology was applied to identify and quantify the 5 surrogates in three carton board materials which intended to be used as packaging materials in direct contact with foodstuffs.

A representative GC/MS chromatogram of a commercially available recycled carton board is presented in Figure 2.

The concentrations of the 5 organic pollutants determined in the 3 cardboard samples are given in Table 2. Quantity of Material (QM) is the maximum permitted quantity of the substance in the finished material or article. QM may be expressed in mg of compound per $\mathrm{dm}^{2}$ of the surface of recycled paper in contact with food or in mg of compound per kg of recycled paper.

In both Figure 2 and Table 2 is shown that among the examined pollutants DIPNs and benzophenone are the compounds with the highest concentrations in the tested cardboards. On the other hand, HTPs exist at extremely low concentrations. However, all the studied compounds were determined at very low concentrations according to the proposed limits for paperboard packages published to the recently issued Industry guideline for the compliance of paper \& board materials and articles for food contact [17]. The concentrations of the two surrogates found in higher amounts are still lower than the proposed limits $\left(0.1 \mathrm{mg} / \mathrm{dm}^{2}\right.$ for benzophenone and "as low as technically possible" for DIPNs). Moreover, according to the policy statement concerning the "paper and board materials and articles intended to come into contact with foodstuffs" of the Council of Europe [18], levels for HTPs in paper and board should be kept as low as reasonably achievable, to minimize migration into food.

Obtained results, compared with the existing proposed limits, are quite encouraging to consider that the tested cardboards can be in principle safely used as food packaging material.

In all three commercially available recycled cardboards additional tests were performed in order to study the migration of the surrogates to foodstuffs, when they are brought in direct contact with the surface of the packages. This is known as a single-side migration test. For the migration tests a food simulant known as Tenax (modified polyphenylene oxide, MPPO) was used. Tenax is considered to be a suitable food simulant for dry foods and dry "fatty foods" such as pastries and cakes. It was also found to be a suitable simulant for pizza base

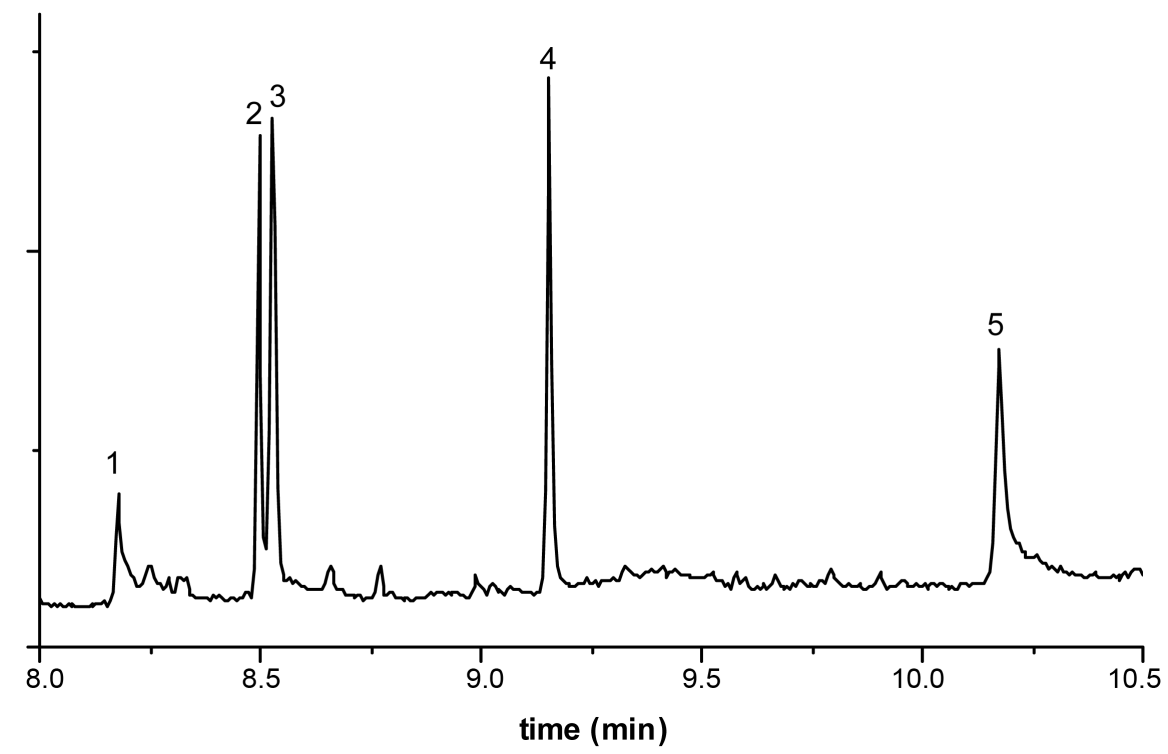

Figure 1. Ion chromatogram of a spiked virgin carton board sample. Peak numbers are found in Table 1. 


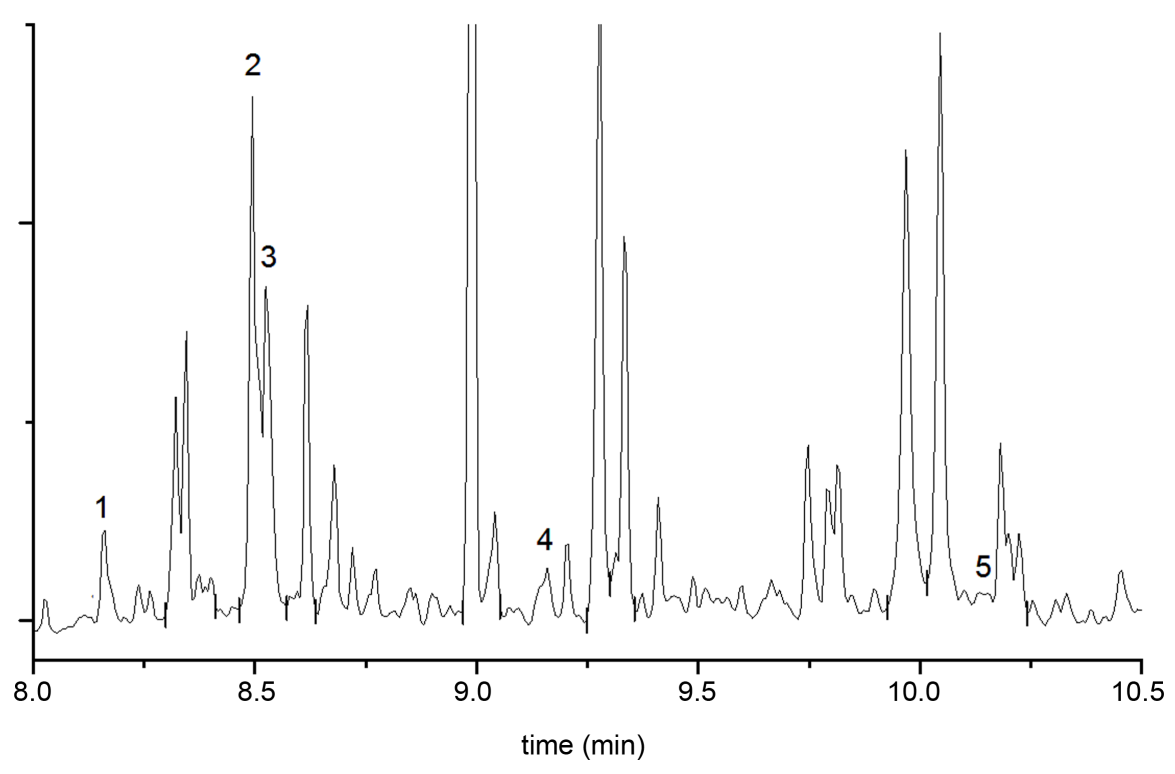

Figure 2. Ion chromatogram of a commercially available recycled carton board. Peak numbers are found in Table 2.

Table 1. \% recoveries of the investigated pollutants.

\begin{tabular}{cccccc}
\hline Compound & $\begin{array}{c}\text { Benzophenone } \\
(1)\end{array}$ & $\begin{array}{c}\text { 2,6-diisopropylnapthalene } \\
\text { (2) }\end{array}$ & $\begin{array}{c}\text { 2,7-diisopropyl naphthalene } \\
\text { (3) }\end{array}$ & $\begin{array}{c}\text { m-terphenyl } \\
\text { (4) }\end{array}$ & $\begin{array}{c}\text { o-terphenyl } \\
\text { (5) }\end{array}$ \\
\hline \% recovery & $85.5 \pm 5$ & $91 \pm 4$ & $93 \pm 2$ & $93.5 \pm 2$ \\
\hline
\end{tabular}

Table 2. Concentrations of organic pollutants determined in the 3 cardboard samples.

\begin{tabular}{ccccc}
\hline & Organic pollutants & Sample BR $\left(\mathrm{mg} / \mathrm{dm}^{2}\right)$ & Sample R $\left(\mathrm{mg} / \mathrm{dm}^{2}\right)$ & Sample R KRAFT $\left(\mathrm{mg} / \mathrm{dm}^{2}\right)$ \\
\hline 1 & Benzophenone & 0.02 & 0.02 & 0.02 \\
2 & 2,6-diisopropylnapthalene & 0.04 & 0.03 & 0.04 \\
3 & 2,7-diisopropylnapthalene & 0.03 & 0.03 & 0.04 \\
4 & m-terphenyl & ND & 0.0003 & 0.0003 \\
5 & o-terphenyl & 0.0003 & 0.0003 & 0.0003 \\
\hline
\end{tabular}

$\mathrm{ND}=$ non-detected.

at higher temperatures for short contact times. However, the extent of migration into Tenax was nearly always greater than that into dry foodstuffs [9] [19].

A chromatogram of the organic pollutants migrated from a recycled cardboard sample into Tenax is presented in Figure 3.

Table 3 gives the mean results obtained with single-side contact of the three recycled cardboard samples with Tenax using the test conditions of $2 \mathrm{~h}$ at $70^{\circ} \mathrm{C}$.

The specific migration limit (SML) values are assigned by the EU Scientific Committee for Food (SCF) to a substance as the maximum amount that is allowed to migrate into food from food contact material. An SML is usually expressed in mg of compound migrated per kg of food or food simulant. For years the general consensus has been that where restrictions for specified substances are listed in EU Directives for plastics, the same restrictions will be adopted for the substances in the Index list of the Paper resolution [20], and this principle is indeed included in a footnote to the Paper resolution [21]. The proposed limits (SML) for benzophenone is $0.6 \mathrm{mg} / \mathrm{kg}$ and for DIPNs and HTPs are "as low as is technically possible".

As it is observed from Table 3, two of the investigated pollutants (m-terphenyl and o-terphenyl) were not detected into Tenax. The other three compounds were generally determined at very low concentrations, not ex- 


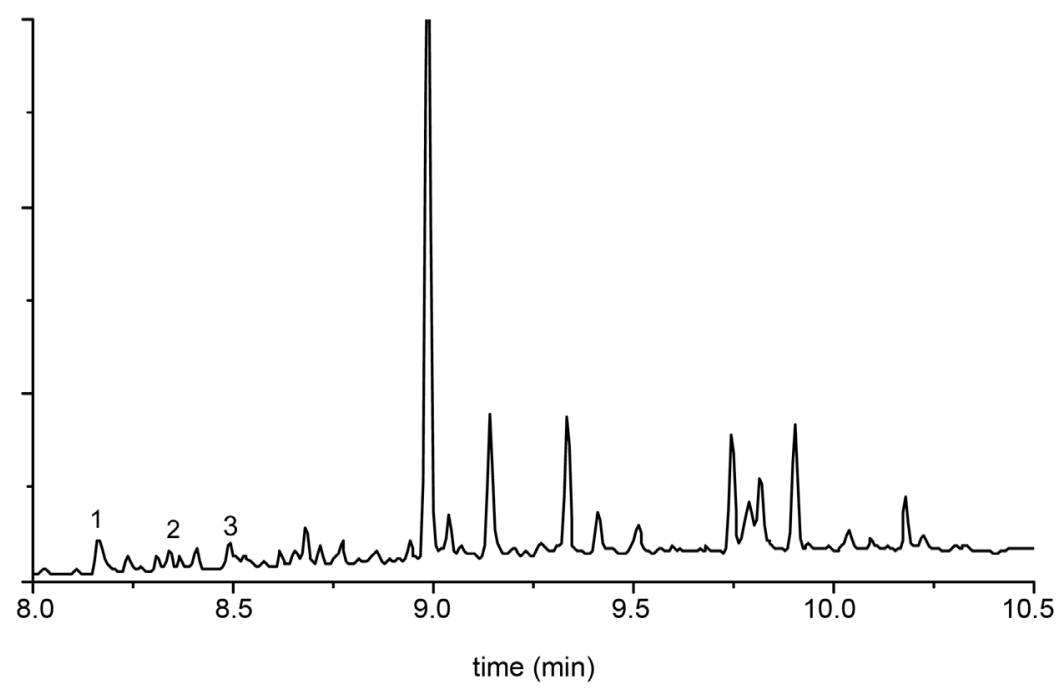

Figure 3. Ion Chromatogram of substances migrated from a recycled cardboard into Tenax. Peak numbers are found in Table 3.

Table 3. Concentrations of migrated organic pollutants from the three recycled cardboard samples into Tenax.

\begin{tabular}{ccccc}
\hline & Organic pollutants & Sample BR $(\mathrm{mg} / \mathrm{kg})$ & Sample R $(\mathrm{mg} / \mathrm{kg})$ & Sample R KRAFT $(\mathrm{mg} / \mathrm{kg})$ \\
\hline 1 & Benzophenone & 0.5 & 0.4 & 0.6 \\
2 & 2,6-diisopropylnapthalene & 0.6 & 1.5 & 1.3 \\
3 & 2,7-diisopropylnapthalene & 0.2 & 1.0 & 0.7 \\
4 & m-terphenyl & ND & ND & ND \\
5 & o-terphenyl & ND & ND & ND \\
\hline
\end{tabular}

$\mathrm{ND}=$ non-detected.

ceeding (in case of benzophenone) the proposed SML value. These results demonstrate again the conclusion drawn above that the investigated recycled cardboard samples can be in principle safely used as packaging material in direct contact with foodstuffs.

\section{Conclusions}

A rapid and reliable method based on ultrasound-assisted extraction followed by GC-MS was developed, to test for 5 organic pollutants [benzophenone, 2 diisopropylnaphthalenes (DIPNs) \{2,6- and 2,7-diisopropylnapthalene and 2 hydrogenated terphenyls (HTPs) \{m-terphenyl and o-terphenyl\}] that can be found as residues in recycled cardboards intended for use as food packaging materials and to test for potential migration levels of these compounds in a food simulant (Tenax).

Three commercially available recycled carton boards were checked with the optimized method for the presence of the above-mentioned compounds and the potential migration of these substances into Tenax, in order to evaluate the suitability of these cardboards to be used as food packaging materials. The results demonstrate that these commercially available recycled cardboard packaging materials can be in principle considered as safe for direct contact with dry foodstuffs.

\section{Acknowledgements}

The authors would like to thank the Food Quality Certification Unit, University of Ioannina, for providing access to the GC/MS instrumentation.

\section{References}

[1] Song, Y.S. and Komolprasert, V. (2000) Analytical Procedure for Quantifying Five Compounds Suspected as Possible 
Contaminants in Recycled Paper/Paperboard for Food Packaging. Journal of Agricultural and Food Chemistry, 48, 5856-5859. http://dx.doi.org/10.1021/jf000512x

[2] Chalbot, M.-C. and Kavouras, I. (2006) Particulate Polycyclic Aromatic Hydrocarbons and n-Alkanes in Recycled Paper Processing Operations. Journal of Hazardous Materials, A137, 742-751. http://dx.doi.org/10.1016/j.jhazmat.2006.04.003

[3] Parigoridi, I.-E., Akrida-Demertzi, K. and Demertzis, P. (2010) A Study on the Suitability of Recycled Paper and Board Intended for Use as Food Packaging Materials. Pre 10-Protection and Restoration of the Environment Conference, Corfu Island.

[4] Anderson, W.A.C. and Castle, L. (2003) Benzophenone in Cartonboard Packaging Materials and the Factors That Influence Its Migration into Food. Food Additives and Contaminants, 20, 607-618. http://dx.doi.org/10.1080/0265203031000109486

[5] Sturaro, A. and Tisato, F. (2006) Contamination of Dry Foods with Trimethyldiphenylmethanes by Migration from Recycled Paper and Board Materials. Food Additives and Contaminants, 23, 431-436. http://dx.doi.org/10.1080/02652030500526052

[6] Boccacci Mariani, M. and Gesumundo, C. (1999) Potential Migration of Diisopropyl Naphthalenes from Recycled Paperboard Packaging into Dry Foods. Food Additives and Contaminants, 16, 207-213. http://dx.doi.org/10.1080/026520399284073

[7] Sturaro, A. and Doretti, L. (1994) Food Contamination by Diisopropylnaphthalenes from Cardboard Packages. International Journal of Food Science and Technology, 29, 593-603. http://dx.doi.org/10.1111/j.1365-2621.1994.tb02102.x

[8] Sturaro, A. and Doretti, L. (1995) Hydrogenated Terphenyl Contaminants in Recycled Paper. Chemosphere, 30, 687694. http://dx.doi.org/10.1016/0045-6535(94)00434-V

[9] Triantafyllou, V.I., Akrida-Demertzi, K. and Demertzis, P.G. (2002) Migration Studies from Recycled Paper Packaging Materials: Development of an Analytical Method for Rapid Testing. Analytica Chimica Acta, 467, 253-260. http://dx.doi.org/10.1016/S0003-2670(02)00189-7

[10] Van Den Dool, H. and Kratz, P.D. (1963) A Generalization of the Retention Index System including Linear Temperature Programmed Gas-Liquid Partition Chromatography. Journal of Chromatography, 11, 463-471. http://dx.doi.org/10.1016/S0021-9673(01)80947-X

[11] Pino, J.A., Mesa, J., Muñoz, Y., Martí, M.P. and Marbot, R. (2005) Volatile Components from Mango (Mangifera indica L.) Cultivars. Journal of Agricultural and Food Chemistry, 53, 2213-2223. http://dx.doi.org/10.1021/jf0402633

[12] Lai, W.C. and Song, C. (1995) Temperature-Programmed Retention Indices for g.c. and g.c.-m.s. Analysis of Coaland Petroleum-Derived Liquid Fuels. Fuel, 74, 1436-1451. http://dx.doi.org/10.1016/0016-2361(95)00108-H

[13] Ainshtein, A.A. and Shulyatieva, T.I. (1972) Retention Indices of Alkyl-and Arylchlorosilanes. Zhurnal Analiticheskoi Khimii, 27, 816-821.

[14] Official Journal of European Communities No. L297/26, 23-10-82, Council Directive 82/711/EEC.

[15] Domeño, C., Munizza, G. and Nerín, C. (2005) Development of a Solid-Phase Microextraction Method for Direct Determination of Pentachlorophenol in Paper and Board Samples: Comparison with Conventional Extraction Method. Journal of Chromatography A, 1095, 8-15. http://dx.doi.org/10.1016/j.chroma.2005.07.119

[16] Gabelish, C.L., Crisp, P. and Schneider, R.P. (1996) Simultaneous Determination of Chlorophenols, Chlorobenzenes and Chlorobenzoates in Microbial Solutions Using Pentafluorobenzylbromide Derivatization and Analysis by Gas Chromatography with Electron-Capture Detection. Journal of Chromatography A, 749, 165-171. http://dx.doi.org/10.1016/0021-9673(96)00428-1

[17] Industry Guideline for the Compliance of Paper \& Board Materials and Articles for Food Contact (2010) Developed by the European Paper and Board Food Packaging Chain: CEFIC (Suppliers of Chemicals) CEPI (Paper and Board Manufacturers) CITPA (Paper and Board Converters) and FPE (Paper and Board Multilayer Manufacturers).

[18] Council of Europe. Resolution on Paper and Board Materials and Articles Intended to Come into Contact with Foodstuffs (Version 4-12.02.2009).

[19] Franz, R. (2002) Programme on the Recyclability of Food-Packaging Materials with Respect to Food Safety Considerations: Polyethylene Terephthalate (PET), Paper and Board, and Plastics Covered by Functional Barriers. Food Additives and Contaminants, 19, 93-110. http://dx.doi.org/10.1080/02652030110085395a

[20] Jickells, S. (1999) Progress with the Paper and Board Resolution at the Council of Europe. PIRA Conference, Paper in Contact with Foodstuffs, Edinburgh.

[21] Council of Europe Resolution on Paper and Board Materials and Articles Intended to Come into Contact with Foodstuffs AP (2002)

http://www.coe.int/t/e/social_cohesion/soc-sp/public_health/food_contact/RESOLUTION\%20AP-2002-1\%20PAPER \%20AND\%20BOARD.pdf 
Scientific Research Publishing (SCIRP) is one of the largest Open Access journal publishers. It is currently publishing more than 200 open access, online, peer-reviewed journals covering a wide range of academic disciplines. SCIRP serves the worldwide academic communities and contributes to the progress and application of science with its publication.

Other selected journals from SCIRP are listed as below. Submit your manuscript to us via either submit@scirp.org or Online Submission Portal.
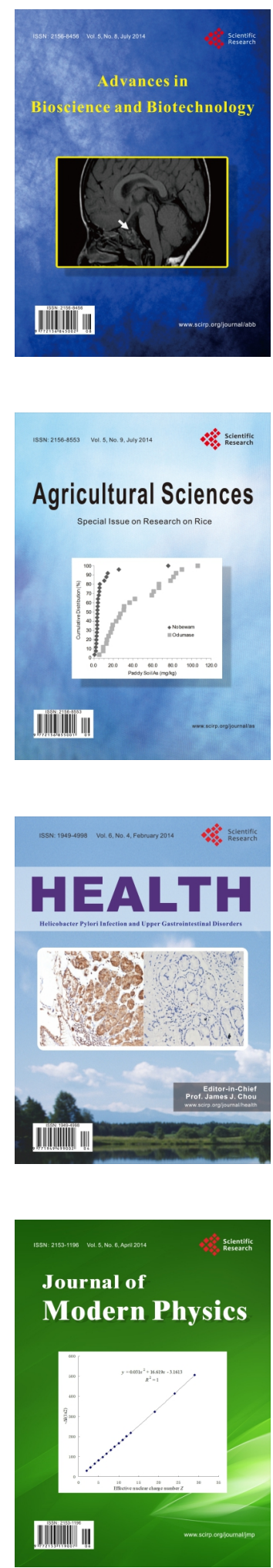
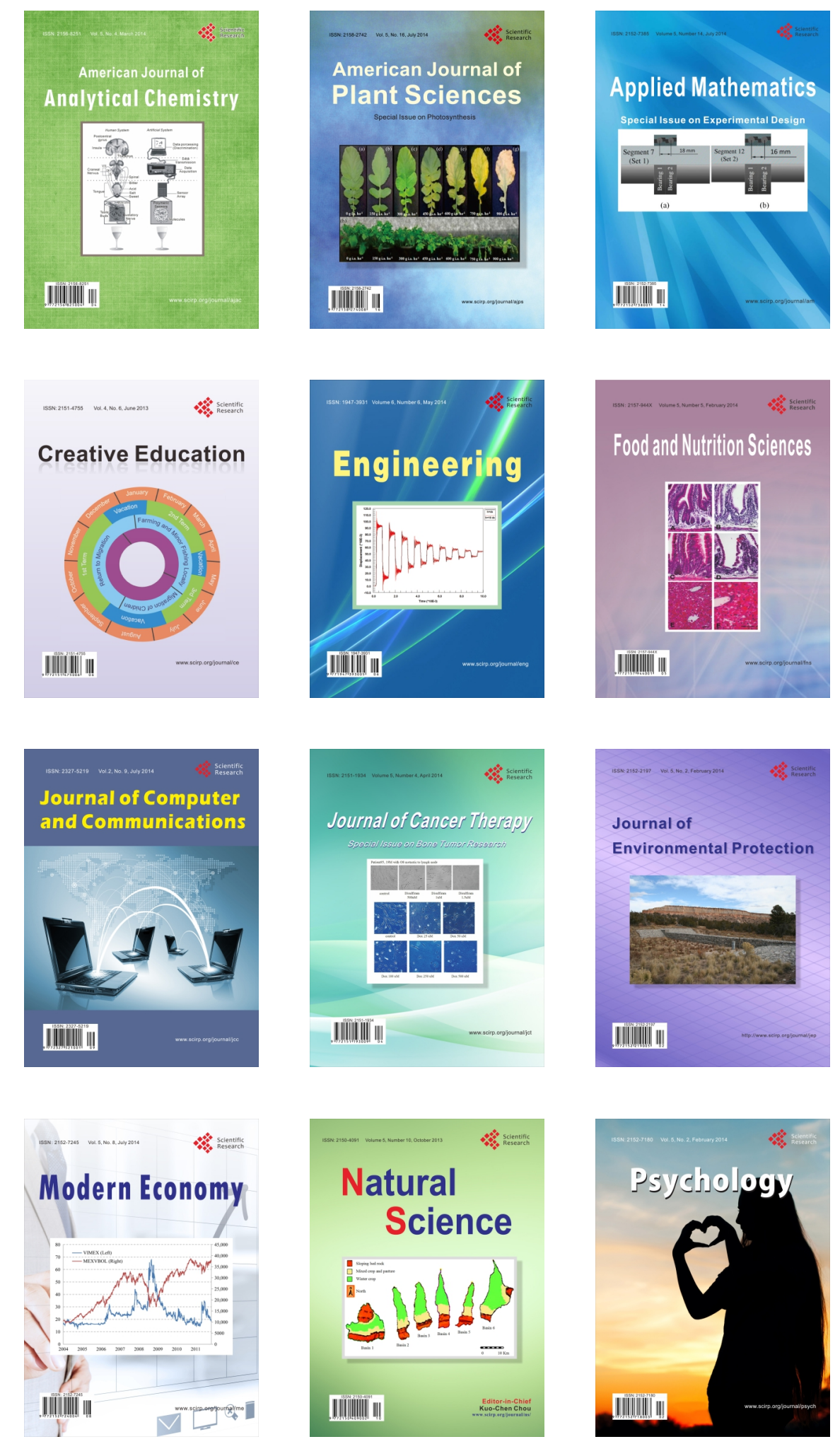